\title{
Management of aggressive fibromatosis (Review)
}

\author{
ZHIJUN ZHANG, JIAN SHI, TAO YANG, TONGJUN LIU* and KAI ZHANG ${ }^{*}$ \\ Department of Colorectal and Anal Surgery, The Second Hospital of Jilin University, Changchun, Jilin 130012, P.R. China
}

Received June 30, 2020; Accepted October 30, 2020

DOI: $10.3892 / \mathrm{ol} .2020 .12304$

\begin{abstract}
Aggressive fibromatosis or desmoid tumor is a rare disease resulting from fibroblasts which do not metastasize. However, desmoid tumors belong to low-grade malignant tumors since they have high potential to infiltrate surrounding tissues, causing high local recurrence rates and may affect surrounding organs, threatening life quality and expectancy. Although surgery, watch and wait, radiotherapy, chemotherapy, high intensity focused ultrasound, ablation techniques or several agents have all been frequently investigated for the treatment of this type of disease, none are deemed as standard therapy for high recurrence rates that have been supported by any data. The present review retrieved literature on treatment options for desmoids to summarize the latest treatment modalities and refine their efficacy, as well as their side effects, in order to provide a more comprehensive treatment reference for clinicians.
\end{abstract}

\section{Contents}

1. Introduction

2. Surgery and watch and wait

3. Radiotherapy

4. Chemotherapy

5. HIFU

Correspondence to: Professors Tongjun Liu or Kai Zhang, Department of Colorectal and Anal Surgery, The Second Hospital of Jilin University, 218 Ziqiang, Nanguan, Changchun, Jilin 130012, P.R. China

E-mail: tongjunliu@163.com

E-mail: champhabell_2020@163.com

*Contributed equally

Abbreviations: LRR, local recurrence rate; PLD, pegylated liposomal doxorubicin; HIFU, high intensity focused ultrasound; RFA, radiofrequency ablation; NSAIDS, non-steroid anti-inflammatory drugs; COX-2, cyclooxygenase-2; MTX/VBL, 'low-dose' chemotherapy with methotrexate and/or vinblastine/vinorelbine; PLD, pegylated liposomal doxorubicin; LD, liposomal doxorubicin; VAC, vincristine and actinomycin \pm cyclophosphamide

Key words: desmoid tumor, aggressive fibromatosis, treatment, regimen
6. Cryoablation technique

7. RFA

8. Hormonal therapy and NSAIDs

9. Summary

\section{Introduction}

Aggressive fibromatosis (AF), also known as desmoid tumor, is a rare type of fibrous tumor with low-grade malignancy and high potential of recurrence $(25-77 \%)(1,2)$, although it usually recurs in situ and does not metastasize distantly. Etiological factors include injury, endocrine disorders (estrogen) and chromosome abnormalities, although familial adenomatous polyposis (FAP) or Gardner's syndrome are all hypothetical (3).

Fibromatoses can be classified by their location into superficial and deep (3-5). Deep fibromatoses usually refer to desmoid tumors (3). This type of tumor may occur from head to foot, which is clinicopathologically categorized into three types: Extra-abdominal (60\%), abdominal wall $(25 \%)$ and intra-abdominal (8-15\%) (6).

Pathogenesis-associated molecules are centered on the cascade reaction of nuclear $\beta$-catenin that is encoded by the catenin b-1 (CTNNB1) gene. The adenomatous polyposis coli (APC) complex induces the degradation of $\beta$-catenin by phosphorylating it, which can be inhibited by the Wnt pathway. Either mutations of exon 3 of the CTNNB1 gene and the $3^{\prime}$ position in codon 1444 of the APC gene or APC dysfunction can result in the accumulation of $\beta$-catenin (7-10).

The most commonly used imaging techniques for desmoids are computed tomography (CT) and magnetic resonance imaging (MRI). Desmoids show similar or slightly higher attenuation compared with skeletal muscle in a non-contrast CT scan and contrast-enhanced CT generally exhibits mild-to-moderate enhancement $(11,12)$. Mesenteric desmoids are typically characterized as a soft tissue mass with radiating spicules extending into the adjacent mesenteric fat at CT (13). As for MRI, desmoids commonly show a heterogeneous pattern appearance, with iso-to hyper-intense signals to skeletal muscle on T2-weighted images and isointense to muscle on T1-weighted images (14). Additionally, 90\% of desmoids demonstrate moderate-to-marked enhancement at gadolinium-based contrast-enhanced MRI (15).

According to The National Comprehensive Cancer Network (NCCN) guidelines, the use of surgery, radiotherapy, systemic therapy and observation are recommended for both 
primary and recurrent aggressive fibromatosis (16). However, the treatment of AF is still controversial since infrequent evidence can validate the satisfactory effects of any treatment means on avoiding local recurrence following administration (6). In this setting, the present review comprehensively retrieved literatures relevant to treatments to summarize the latest treatment modalities or drugs listed in the following chart and detailed the efficacy of each modality along with side effects or limitations, which would facilitate in attaining a better clinical decision.

The treatment modalities of desmoids discussed include: i) Surgery and watch and wait; ii) radiotherapy; iii) chemotherapy [tyrosine kinase inhibitors (imatinib, sunitinib, sorafenib), methotrexate and vinblastine (MTX/VBL), conventional chemotherapy with doxorubicin (including PLD; LD) \pm dacarbazine, loco-regional chemotherapy, vincristine and actinomycin and cyclophosphamide (VAC), other agents (cyclophosphamide, pazopanib, hydroxyurea]; iv) hormonal therapy and non-steroidal anti-inflammatory drugs (NSAIDs) [selective estrogen receptor modulators (tamoxifen, raloxifene, toremifene) with or without NSAIDs, luteinizing hormone-releasing hormone analogue (leuprolide), other hormones that could antagonize estrogen (medroxyprogesterone, testosterone, progesterone]; v) high intensity focused ultrasound (HIFU) treatment; vi) ablation technique [radiofrequency ablation (RFA), CT-guided percutaneous cryoablation]; vii) non-NSAIDS (sulindac, indomethacin, meloxicam, celecoxib); viii) other agents in clinical trials [1,25-(OH)2-vitamin D3 treatment, interferon- $\alpha$, retinoic acid, tranilast, predinisolone].

\section{Surgery and watch and wait}

Surgery. Surgery has been widely used in all types of resectable desmoid tumors. Surgery is the first-line treatment for tumors with a clear margin in most cases (17). It was found that patients in case reports with intra-abdominal desmoids attain a non-recurrent duration varying from $<12$ months (18) to 30 months (19), excluding those who were lost to follow up and cases that were not mentioned. In addition, the local recurrence rate is $8-31 \%(20,21)$ after surgery with a clear margin. A study involving 176 patients receiving a complete excision with a clear margin showed a 10-year local recurrence rate of $58 \%$ (22). A meta-analysis containing 1,005 patients receiving surgery alone showed a recurrence of $30 \%$ (23). Other reported recurrence rates are even higher. It was reported that local recurrence rates still range between $19-77 \%$ with a wide excision (24,25). However, according to a systemic review (26), the local control rate of desmoids with $\mathrm{R} 0$ excision from several studies vary from $47-86 \%$, which is not so disappointing.

As for the impact of margin on prognosis, there are different views (16). Several studies (27-29) favored that negative excision did not make a difference in prognosis, however others (16) did not discover such an association. For example, R0 excision did not favor R1 excision in progressive-free survival (PFS) in a univariate analysis (16), but a multivariate proportional hazards regression analysis revealed that state of margin significantly impacted the prognosis (positive vs. negative; $\mathrm{P}=0.001$; relative risk, 2.9) (30). Considering its infiltrate characteristics, it is difficult to distinguish the boundaries of desmoids. Simultaneously, an aggressive excision for negative margin cannot exactly assure a better outcome, which may sacrifice important function or even lives. Hence, the benefits and faults of excision should be carefully considered. In addition, post-operational radiotherapy is supposed to improve the prognosis of those with a positive margin after excision; the 10-year recurrence rates for patients treated with surgery alone and patients treated with combined surgery and radiation therapy were $54 \%(95 \% \mathrm{CI} ; 37-69 \%)$ and $31 \%$ (95\% CI; 15-53\%), respectively ( $\mathrm{P}=0.007)$ (30). Overall, it is risky and difficult to perform complete excision.

Surgery has substantial limitations. To begin with, although wide local excision is the gold-standard treatment for desmoid tumors in the past, no solid evidence has affirmed that surgery yielded superior outcomes over other treatments (16). Even other conservative measures are favored as these measures have lower complication rates. Secondly, scientists have found that in a series of 203 patients with extra-abdominal desmoid tumors treated with surgery over a 35-year period, patients without antecedent interventions had longer disease-free survival and presence of recurrence was the prognostic factor indicating strong recurrence (31). Given that surgery, as a type of trauma, is an etiological factor for desmoid tumors and long-term recurrence rates of surgery are quite high, surgery should be treated with caution. Simultaneously, the boundaries of the tumors are hard to distinguish intraoperatively from scars and connective tissue, causing difficulty in R0 resection (32). Recurrence after surgery not only occurs in situ but also in adjacent areas, as it is unable to preserve connective tissues well (33). Under these conditions, repeated recurrent desmoid tumors would tend to invade surrounding tissues in a concentric way if treated with surgery, which would gradually invade more tissues and important organs or major vessels. Radical surgery is always infeasible in mesenteric desmoid disease as the mortality of surgery is $10-60 \%$ and the recurrence rate is $78 \%$ (34). Surgery itself subjects patients to post-operational risks in addition to its high recurrence rate (up to 40\%) (3).

Watch and wait. With multi-institutional studies having demonstrated spontaneous regression rates of $28-50 \%$ in recent years (35-37), interventions should be treated discreetly. The effect of the watch-and-wait policy is endorsed by the number of cases. A clinical study demonstrated growth arrest in two thirds of the nonsurgical group (38). In a study (16) involving 27 patients with sporadic desmoid tumors treated with the watch-and-wait policy, only six progressed with a delay to progression ranging from 7.8 to 46.2 months. The remaining 21 patients avoided surgery with an ideal outcome, in which the disease attained a stable course, and even five cases regressed spontaneously. Cho et al (39) reviewed five studies in which desmoids are managed by the watch-and-see policy with varying rates of spontaneous regression from $65.1-96.1 \%$.

The watch-and-wait policy is recommended by NCCN 2018 guidelines where observation applies to selected patients in non-life-threatening situations. However, it is confusing to judge the criterion for 'selected patients', and Zhao et al (40) believes that surgery should be performed once the disease has progressed. Others believe that the endpoint of this type of modality depends on the patient's symptoms, medical status and the biological properties of the tumor (41). Briand et al (42) 
reported a low probability of transiting to other salvages which was only $5.7 \%$ at 1 year and 9.6 at 5 years. Hence, it seems that watch and wait is quite safe and may be a promising treatment for first-line therapy, especially considering the high local recurrence rate of other interventions, along with its low rates of dropping out.

\section{Radiotherapy}

Radiation therapy has been used in patients with inoperable desmoid tumors, local recurrence or incompletely excised lesions (43-45). The results from radiation therapy demonstrated local recurrence rates of $25 \%$ (46). A systemic review revealed a control rate following radiotherapy varying from $65-83 \%$ (26). Bishop et al (47) reported 5- and 10-year local recurrence rates of 71 and $69 \%$, respectively. Smith et al (26) found that the local control rates of desmoid tumors treated with radiotherapy ranged between 65 and $83 \%$ during a reported follow-up of 105 months (range, 72-120). Hence, it seems that exclusive radiotherapy cannot attain satisfactory local control, although a systemic review revealed a control rate after radiotherapy varying from $65-83 \%$ (26).

According to the guidelines from the $\mathrm{NCCN}$, radiotherapy is often a supplementary treatment indicated in cases of AF that present as large tumors or with positive margins (48). Nuyttens et al (49) noted that the local control rate of surgery combined with post-operational radiotherapy group was $75 \%$, which is better compared with the exclusive surgery group while both margins are positive.

Radiotherapy for desmoids has several disadvantages. Firstly, it can decrease local recurrence, but may account for post-irradiation fibrosis, joint contracture and neuropathy. Moreover, the duration to achieve complete resolution may be as long as several months (50). Secondly, Chen et al (48) reported a desmoid tumor developed from radiation treatment for keloids, which indicated that radiotherapy may be a causal factor of AF. Thirdly, some studies cannot validate the efficacy of adjuvant radiotherapy for desmoids following incomplete surgical resection $(51,52)$. Fourthly, radiotherapy is effective for both extra-abdominal and abdominal wall tumors as relevant side effects are quite less compared with radiation enteritis that is in high risk, which occurs at mesenteric desmoids if treated by radiation (53).

\section{Chemotherapy}

Chemotherapy is used for inoperable progressive lesions in occasions where surgery or radiotherapy would cause morbidity $(50,54)$. The overall response rates to combination chemotherapy are $17-100 \%$ (55). The duration of response to chemotherapy in pain relief is usually short, while longer in radiological tumor shrinkage or stabilization, which may continue for months before an expectant response (56). Chemotherapy is used for primary or recurrent desmoids and adjuvant treatment ahead of operation or after operation.

According to literature, agents used in DT chemotherapy include tyrosine kinase inhibitors (TKIs), methotrexate, vinblastine, vinorelbine, doxorubicin, dacarbazine, carboplatin, melphalan, vincristine, actinomycin, cyclophosphamide and hydroxyurea. They are used alone or in combination with one another. Different combination chemotherapies constitute various regimens that apply to different situations and characterize a variety of features. The present review summarized the present common regimens and their efficacy to assist in clinical decisions.

TKIs. TKIs were found to have response rates of 5-20\% at 1 year, and the rate of progression-free disease varies between $60-70 \%$ (57,58). An uncontrolled, non-randomized, phase III study showed high rates of stable disease up to $50-80 \%(59,60)$. Imatinib, sorafenib and sunitinib are common TKI drugs targeted for desmoids, which have been extensively studied (60-66).

Imatinib therapy has a response rate of $<10 \%$ for solid tumors (41). Imatinib treatment is reported to attain progression-free survival (PFS) rates of $58 \%$ at 24 months and $55 \%$ at 36 months $(59,60)$. A prospective phase II trial demonstrated that PFS rates were $94 \%$ at 2 months, $88 \%$ at 4 months and $66 \%$ at 1 year. However, it is associated with toxicities such as grade 3/4 neutropenia, rash, fatigue, abdominal pain, diarrhea, myalgias and asthenia $(59,60)$.

Skubitz et al (67) reported a case of multifocal desmoids that was refractory to imatinib but responded well to sunitinib. Based on the aforementioned study, a prospective multicenter phase II study (68) evaluated the efficacy of sunitinib, in which the rates of partial response and stable disease were 26.3 and $42.1 \%$, respectively. Additionally, the 2-year progression-free and overall survival rates were 74.7 and $94.4 \%$, respectively. Side effects that occurred in $>5 \%$ of patients included neutropenia (33.3\%), diarrhea (5.3\%) and hand-foot syndrome $(5.3 \%)$. In the early phase of sunitinib, mesenteric mass bleeding, bowel perforation along with bowel fistula due to bowel mass necrosis were respectively observed in three patients. The author believed sunitinib to be a useful management of non-mesenteric desmoids.

A study elucidated the efficacy of sorafenib and its side effects (69). Sorafenib is administered as the first-line or substitute treatment with a striking clinical benefit comprising 16 of 22 patients. Moreover, no difference was found in radiological benefit $(\mathrm{P}=0.9)$. Toxicities include hand-foot syndrome, fatigue, skin rash, trichodynia, hypertension, mild alopecia and diarrhea, which can be controlled with dose reductions and the use of antidiarrhea and antihypertensive drugs. However, another double-blind, phase III trial study comparing the efficacy of sorafenib vs. placebo demonstrated objective response rates [sorafenib vs. placebo: 33\% (95\% CI, 20-48\%); $20 \%(95 \% \mathrm{CI}, 8-38 \%)]$. In addition, the 2-year PFS rate was $81 \%(95 \% \mathrm{CI}, 69-96 \%)$ in the sorafenib group and $36 \%$ (95\% CI, 22-57\%) in the placebo group (hazard ratio for progression or death, 0.13; 95\% CI, 0.05-0.31; $\mathrm{P}<0.001$ ). The sorafenib group has similar side effects as the previous study. In addition, desmoids harboring the S45F mutation with anti-cytotoxic effects caused by autophagy may respond well to sorafenib and hydroxychloroquine (an autophagy inhibitor), as reported by Braggio et al (70).

$M T X$ and $V B L$. The combination of MTX and VBL (MTX/VBL) were studied for desmoid treatment and yielded a promising effect (54,71-74). According to the literature, the response rate for MTX/VBL varied from 31-52\% (72,75), 
but the data is too conservative if more prognosis data are included. A systematic review that evaluated the efficacy of MTX/VBL combination chemotherapy on primary or recurrent desmoids showed a mean response rate of 36\% (11-57\%) or $85 \%$ in patients with stable disease (71). In addition, it was reported that patients with stable disease progression accounted for $>35$ and $>28 \%$ attain a PFS duration of a mean of 43.4 months in a phase II study examining the effect of MTX/VBL therapy on children (72). Another similar phase II study (73) focusing on adults showed a $100 \%$ rate of clinical benefit with ratios of stable disease and partial response accounting for 60 and $40 \%$, respectively. The percentage of patients with a 10 -year PFS interval was up to $67 \%$. As reported, young age is an indicator of bad prognosis, which applies to those treated with chemotherapy according to aforementioned studies.

This combination modality also has some side effects, although the rates of adverse effects are low according to studies on children $(54,72,75)$. Neutropenia (myelosuppression or myelotoxicity) $(71,72)$ was reported to be the main adverse effect. Moreover, anemia, nausea, mild alopecia, vomiting and elevation in hepatic transaminases, which were reversible with interruption of chemotherapy, are all common side effects $(54,72,73)$. The duration of response to MTX/VBL is longer in children, typically $\sim 9$ months (76). Due to toxicities of this modality, the combination of vinorelbine and MTX can substitute the previous regimen for decreasing toxicities without sacrificing the response rate (77). Considering its low rates of side effects which are dominantly due to myelotoxicity, which would make it feasible to impose prophylaxis ahead of time, the MTX/VBL modality is a promising and safe modality.

Conventional chemotherapy with doxorubicin, including pegylated liposomal doxorubicin (PLD) and liposomal doxorubicin (LD) with or without dacarbazine. Conventional chemotherapy is generally applied to patients who fail the 'low-dose' regimen (78). PLD or LD is a variant of doxorubicin (a type of topoisomerase II inhibitor), which is decorated by liposomes with or without polyethylene glycol for decreasing the cardiotoxicity of doxorubicin (79). Several studies have shown its high rates of response. A study reported that four patients with advanced desmoids responded well to PLD without significant toxicities (80). Another study involving 12 patients demonstrated satisfactory results in which the rate of stable disease was up to 64 , and $75 \%$ of patients did not attain progression during the entire follow up with a median duration of 14 months (81). A retrospective review of pediatric patients analyzed the effects of LD and an average $4.5 \%$ reduction of tumor size and a median PFS time of 29 months, which showed more ideal results (76). In addition, doxorubicin can also be used to assist carboplatin in further reducing the tumor size by intralesional injection, which was reported in a cohort study (82). Additionally, some researchers have discontinued doxorubicin or adjusted the dose of carboplatin to a cumulative of $400-500 \mathrm{mg} / \mathrm{m}^{2}$, due to its cardiotoxicity. Although promising, doxorubicin also has some side effects, such as palmar-plantar erythema, mucositis, cardiotoxicity (83) and dose-relevant reduction (81).
Loco-regional chemotherapy. Loco-regional chemotherapy is rarely reported in some cases, in which TNF- $\alpha$ and melphalan is perfused into isolated limbs (84). Data from three sarcoma centers of the European Organization for Research and Treatment of Cancer indicated that TNF- $\alpha$ and melphalan could prevent amputation in $88 \%$ of patients with advanced disease. Up to $61 \%$ showed regression or stabilization of disease during a median follow-up of 84 months and the PFS time was as long as 27 months (85). It acts as a substitute in patients affected by carcinoma in extremities, especially for those who have multifocal desmoids of hand or foot (84). This regimen helps patients avoid routine operation since state of stable disease or slow regression is often observed in patients after therapy (84).

$V A C$ regimen. The VAC regimen was firstly reported by Raney (86) to treat fibromatosis in a series of cases including six patients aged 3 months to 7 years with primary or recurrent desmoid tumors. This regimen is an alternative to doxorubicin-based chemotherapy with comparable responses, particularly in pediatric patients. The main side effects of VAC are sterility and carcinogenesis $(55,87)$. The duration from the first administration of the VAC regimen to response is estimated to be at least 12 weeks, according to the Intergroup Rhabdomyosarcoma Study (88). However, others (89) believed that VAC regimens should be given up if no response was observed within a duration of 16-20 weeks following the initial administration. Additionally, most clinical reports regarding the VAC regimen involve children. Prognostic data are not available considering the rare cases and clinical reports, which can be supplemented by more trials.

The present review listed five different regimens that are formed by combinations of different agents and commonly used in desmoid chemotherapy, although other agents such as hydroxyurea (76), $\gamma$-secretase inhibitor (90) and pazopanib (91) are also involved in chemotherapy trials. These five combinations are mainstream chemotherapy regimens whose efficacy and side effects have not been comprehensively reviewed in previous literatures.

\section{HIFU}

HIFU is a novel, minimally invasive treatment based on thermal ablation. Adjacent tissues are not involved in this treatment as it is based on ultrasound beams that are precisely focused on the target locations to produce thermal coagulation necrosis $(92,93)$. No virtual insertion operation, as well as energy that is highly centralized, guarantee normal tissues out of iatrogenic trauma, which may contribute to desmoid tumors (94). Facial tissues, unlike the targeted area (where the rate of absorption exceeds the rate of heat emission and would undergo necrosis due to accumulation of heat) can be passed through by focused ultrasound energy, hardly harming the patient (95).

Several studies have illuminated the efficacy of HIFU treatment on desmoid tumors. Zhao et al (40) reported the first case of HIFU treatment in aggressive breast fibromatosis with multiple recurrence following surgery. Ghanouni et al (96) applied HIFU treatment to 15 selected patients with extra-abdominal desmoids. The mean tumor volume decreased to $63 \%$ with 
significant improvement in pain. HIFU treatment can also be used to treat intra-abdominal desmoid tumors. Shi et al (97) reported four patients with intra-abdominal desmoid tumors treated with HIFU treatment. The MRI showed at least $80 \%$ ablation in all cases and one patient showing $100 \%$ ablation during a follow up for 19-46 months (mean, 34 months). Similarly, abdominal wall desmoid tumors are treated in the study by Wang et al (98), aiming to evaluate the therapeutic efficacy of HIFU ablation for the treatment of extra-abdominal desmoid tumors. It seems that HIFU more often served as a salvage for recurrent desmoid tumors. However, the present study found two cases where HIFU treatments are used to treat primary desmoid tumors with ablation ratios of $100 \%$. Hence, the present study proposes that HIFU can be a curative treatment. In contrast, for recurrent desmoid tumors, HIFU treatment is performed as palliative treatment (98).

In fact, this type of minimally invasive treatment modality does have some side effects. Zhao et al (99) reported acroparaesthesia of the lower limb and platelet decrease in patients after treatment. Wang et al (98) reported swollen skin, first-degree skin burns, mild pain and low-grade fever in HIFU-treated patients. In addition, similar adverse events, such as those in surgery, including adjacent important vessels or organ injuries that affect functions or even life-threatening may occur. Therefore, a balance should be struck between eradication and decreasing side effects. According to different goals of HIFU treatment, a margin of at least $1 \mathrm{~cm}$ can satisfy curative in situ eradication for primary desmoid tumors not involving major neurovascular structures. Additionally, ablation areas should include as much planned areas without injuring major neurovascular structures as possible, which can achieve better local control, taking side effects of palliative treatment outcome in recurrent desmoid tumors in consideration (98).

HIFU treatment is a promising means in desmoid tumor treatment. Although it has side effects, it is characterized as highly 'precise excision' and relatively minimally invasive. More research should focus on its potential as a curative means, based on presently rare primary cases in which patients are cured.

\section{Cryoablation technique}

Percutaneous cryoablation. Percutaneous cryoablation currently delivers room temperature argon gas through a sealed, segmentally insulated probe to cause rapid cooling locally due to the Joule-Thomson effect (100). According to Kurup and Callstrom (101), percutaneous cryoablation is a less-invasive treatment potential to cure desmoid tumors. A study (33) was performed to evaluate the efficacy, safety and advantages of cryoablation for both first-line treatment and remedial treatment of extra-abdominal desmoid tumors. A total of $89 \%$ of patients reported improvement and the average change in viable volume was $-80 \%$ (range, -100 to $+10 \%$ ) with complete response of $36 \%$, partial response of $36 \%$ and stable disease of $28 \%$ after a 1-year follow-up. The high rate of incomplete ablation, achieving a $90 \%$ clinical response rate as well as its less-invasive feature suggested that percutaneous cryoablation is a promising modality to cure extra-abdominal desmoid tumors. Similar results affirmed the efficacy of cryoablation for its high rate of local control $(102,103)$. In addition, cryoablation has been investigated as both first-line and salvage treatment modality (33) and an ideal outcome has affirmed its reliability.

Cryoablation owns several advantages over other therapies. In contrast to a $23 \%$ recurrence rate in a 2 -year follow-up after $\mathrm{R} 0$ excision by imaging, complete $\mathrm{A} 0$ ablation extinguishes diseases (16). Moreover, it was reported that the recurrence after cryoablation often occurs in situ. However, recurrence sites after surgery are located in adjacent tissue, complicating further therapy by causing neurovascular injury. This is due to connective tissues or compartments being well-preserved in cryoablation, unlike in surgery (33). Cryoablation has better local control which may substitute surgery or radiotherapy, neither of which alone could attain an ideal local control (47). Finally, nearly all cryoablation is less invasive and patients would return home within one or two weeks, unlike in the surgery group depending on the complexity of excision and recovery state (33).

Percutaneous cryoablation owns several limitations or side effects. Mostly, this type of modality applies to extra-abdominal and abdominal wall desmoid tumors and no reports reported treating intra-abdominal desmoid tumors with this modality. Furthermore, longer term follow up is needed to assess how $\mathrm{A} 0$ cryoablation compares to the $\mathrm{R} 0$ 5-year recurrence rate of almost $40 \%$ (47). Injury to skin and nerves are the most common complications caused by cryoablations.

\section{RFA}

RFA exploits high-frequencies $(375-500 \mathrm{kHz})$ that are delivered by a special electrode to cause local heating effect of tumors, which would result in protein denaturation and coagulation necrosis in order to decrease or exterminate tumors (100). It is a minimally invasive therapy widely applied to treat unresectable, malignant tumors and some benign lesions using a fine needle electrode inserted into lesions with imaging guidance $(100,104,105)$, which requires a shorter anesthetic time without using an operating room compared with surgery (19). RFA can be applied in abdominal wall desmoids (106).

Some studies have tried this modality on recurrent desmoid tumors which failed to response to surgery. Complete ablation without any relapse was observed in all four patients during a mean 30-month follow-up (107). Tsz-Kan et al (108) reported a case of successful long-term local control of recurrent fibromatosis treated by RFA. Barrow et al (106) used RFA to treat a patient with desmoid tumors in familial adenomatous polyposis (FAP) which caused a decrease in tumor size and relief of symptoms.

RFA has some advantages in treating desmoids in FAP, such as aversion of surgery, tumor reduction, inhibition of growth and symptom relief (106). Simultaneously, this type of modality also has several shortcomings. Firstly, RFA has the potential to cause some side effects associated with ablation. For example, cellulitis and soft tissue necrosis were both mentioned in a study by Ilaslan et al (107), who applied CT guidance for assistance in RF ablation. Ko and Kang (109) suggested that CT showed untidy margins of desmoid tumors with the same density as muscles, which potentially resulted in over-ablation-induced skin burns. This can be improved by transition to using MRI guidance that 
can image a definite margin. Real-time ultrasound images, especially combined with the 'moving tip' technique, have been investigated for their ability to assist in ablation to treat superficial lesions. Secondly, it was reported that RFA can cause some common complications such as pain, bleeding, infection and visceral injury while desmoid tumors exist in abdominal walls $(106,107)$. Thirdly, RFA may stimulate tumor growth (106).

\section{Hormonal therapy and NSAIDs}

Either hormonal treatments or NSAIDs were reported to be used for first-line therapy or unresectable, recurrent or progressing desmoids, solely or in combination (77,110-113). Common hormonal treatments used for desmoids include selective estrogen receptor modulators (tamoxifen, raloxifene and toremifene), leuprolide, medroxyprogesterone, testosterone and progesterone. The corresponding NSAIDs contain sulindac, indomethacin, meloxicam and celecoxib.

Hormone-based therapy. Hormonal therapy typically consists of the use of selective estrogen receptor modulators (tamoxifen, raloxifene and toremifene) and occasionally involves the use of luteinizing hormone-releasing hormone analogues (leuprolide) and other hormones that antagonize estrogen (medroxyprogesterone, testosterone and progesterone).

Tamoxifen, raloxifene and toremifene are all anti-estrogen agents that are used for desmoids. Lackner et al (114) described the efficacy of tamoxifen and toremifene with a response rate of $65 \%$ and scarce side effects in treating desmoids. According to a systemic review, the overall response (complete plus partial response) rates and disease stabilization rates are similar in tamoxifen and toremifene (115), which are 58 and $18 \%$ vs. 56 and 19\%, respectively. Moreover, according to Okuno (116), dosage increases of tamoxifen are not more effective although some clinical trials elevate the dosage of tamoxifen when its effects are not satisfactory. Toremifene is effective in some cases refractory to tamoxifen. Toremifene does not exhibit long-term complications (117-120), however it should be reserved for patients with a history of venous thromboembolism or pulmonary embolism given the risk of thromboembolic events observed following long-term treatment with raloxifene.

Some reports have demonstrated the effects of anti-estrogens combined with other drugs. Hormone-based treatment showed a response in $40-51 \%$ of cases $(115,121)$. It was reported that $\sim 50 \%$ of patients with mesenteric desmoids respond to anti-estrogens (108). In addition, a systemic review focused on the effects of anti-estrogen with or without other drugs, such as NSAIDs, concluded that overall response (complete response plus partial response) rates and disease stabilization rates are $51 \%(46 / 91)$ and $27 \%$ (24/91), respectively in desmoids with FAP, and 48\% (24/50) and 38\% (19/50), respectively, in sporadic desmoids (115). The author of this review also found a higher rate of complete or partial response in anti-estrogen alone compared with in combination with NSAIDs $(\mathrm{P}<0.001)$. In addition, the regimen that combined sulindac (an NSAID) with anti-estrogen agents was tapered after a median duration of medication of $42.4 \pm 24.3$ months, which could not be influenced by genetic state, sex or a concrete type of anti-estrogen agent applied to desmoids (122).

The most common hormone-based therapy is tamoxifen in combination with or without other drugs. Bauernhofer (123) reported a female patient with FAP suffering from recurrent unresectable intra-abdominal desmoids. Tamoxifen with subsequent goserelin acetate (an analogue of the luteinizing hormone-releasing hormone) attained a PFS duration of up to 17 months, and tumor progression was again inhibited by goserelin acetate combined with IFN- $\gamma$. Tamoxifen combined with sulindac have been well investigated in clinical trials. A phase II study within the Children's Oncology Group demonstrated overall response, 2-year PFS and survival rates of 36\% (95\% CI, 0.23-0.48) and 96\%, respectively (124). This study also reported relevant side effects including gastritis, emesis, hemorrhage events, ocular problems, pain in the abdomen or head, embolism-related events, tinnitus, prolonged QTc interval, fever, fatigue, skin breakdown/decubitus, nausea, elevated alanine transaminase/aspartate transaminase ratio, hypomagnesemia, ovarian cysts and dizziness. Another systemic review revealed that the side effects of anti-estrogen occur at a lower rate compared with surgery and chemotherapy (125). Simultaneously, selection of drugs was significantly impacted in cases of side effects of corresponding drugs (122); raloxifene was preferred in female patients in order to reduce the risk of endometrial cancer and ovarian cysts, while male patients were preferably administered with tamoxifen.

NSAIDs. NSAIDs used to be the first-line therapy due to their low toxicity (39). Common NSAIDs used for desmoids include meloxicam, indomethacin, sulindac and celecoxib.

Sulindac is always used in combination with tamoxifen. Tsukada et al (126) found that the overall response rate was up to $57 \%$ with a mean response time lag of 24 months in assessing the efficacy of sulindac in 14 patients with FAP suffering from recurrent desmoids. Quast et al (122) reported common side effects of sulindac such as high elevation in liver function tests which occurred in $1.5 \%$ of patients and venous thrombosis in $2.2 \%$ of patients.

Meloxicam, which belongs to the cyclooxygenase-2 (COX-2) inhibitor agent group, has shown its effects in managing extra-abdominal desmoid tumors (127). A retrospective review analyzing the outcomes of primary or recurrent extra-abdominal desmoid tumors treated with meloxicam showed state of partial relief or stability in $65 \%$ of patients. The rates of dropping out from this treatment remain at $35 \%$ at both 1 or 5 years (39). Meloxicam efficacy was demonstrated by Nishida, who followed 20 patients treated for 3-81 months; over the 44 months of follow up, $95 \%$ of patients experienced equal to or better than stable disease (128).

Yang et al (129) first reported a case of patients with aggressive fibromatosis (desmoid tumor) treated with celecoxib (a type of NSAID) under the guidance of genetic testing, in which the patients demonstrated significant regression without any signs and symptoms during a 20-month follow-up. They recommend this modality under the condition that genetic testing showed the presence of p.T41A mutations on the CTNNB1 gene, which could predict whether the patient is sensitive to the COX-2 inhibitor celecoxib or not. A previous study used celecoxib 
combined with excision, in which complete remission without local recurrence was accomplished within a duration of a 24-month follow-up (130). However, multicenter randomized controlled trials are required in the future.

An early report indicated that indomethacin at an oral dose of $100 \mathrm{mg} / \mathrm{d}$ caused resolution of the tumor (131). According to the report, this drug caused complete resolution of desmoids which was partially responsive to radiotherapy in one previous case. Another case showed immediate but short response and resumed resolution for 14 months with large doses of ascorbic acid being supplemented with indomethacin. The remaining two cases received combination indomethacin from the beginning and showed shrinkage of tumors during the entire follow-up.

In addition, other drugs used for the attempted treatment of desmoids showed certain efficacy such as 1,25-(OH)2-vit amin D3 (132,133), IFN- $\alpha$ (134), retinoic acid, tranilast (135), predinisolone $(136,137)$ and ascorbate $(138,139)$. These strategies are not included in conventional therapy but may act as second line therapies. Ferah et al (133) reported a female patient with a huge desmoid mass in the right shoulder region, resistant to radio-chemo-hormonal therapy, that eventually responded to radio-chemo-hormonal therapy. A clinical trial including 13 patients who previously received surgery for desmoids were recruited to examine the efficacy of further management of IFN- $\alpha$ with or without tretinoin (134). The results (seven patients had no evidence of disease and a mean disease-free interval of $22 \pm 18$ months; in two patients, progressive disease occurred after only 7 and 9 months, respectively, during observation) revealed that this regimen could significantly prolong the disease-free interval. Tranilast was administered to a Japanese male with desmoid tumors on his chest wall who refused to surgery-radio-chemical therapy and the tumor was successfully controlled (135). Predinisolone was reported to induce intra-abdominal desmoids with FAP to regress or even disappear in an unresectable case (137).

\section{Summary}

As aforementioned, the present review comprehensively summarized the efficacy of recent interventions on desmoids along with their side effects or limitations. Surgery, NSAIDs, hormonal therapy, chemotherapy and radiation therapy have all been recommended as either first-line or alternative treatments. However, neither treatment modality could exhaustively eradicate tumors without recurrence supported by sufficient evidence. An increasing number of clinical trials aim to supplement existing evidence and continue to investigate novel potential drugs for the treatment of desmoids, which are necessarily characterized to provide pivotal information in order to serve in clinical practice better.

Some crucial points should be supplemented. Firstly, surgery, chemotherapy or radiotherapy should be used with caution. Patients with recurrent desmoids after excision and/or radiation have poor response to broad spectrum chemotherapy. In addition, taking into consideration that $\sim 50 \%$ primary desmoids would recur and young age is indicative of a high chance of relapse, it is unwise to treat children with chemotherapy alone $(21,140,141)$. Simultaneously, radiation is a clear carcinogenic factor, increasing risk of tumors, especially in children (48). Hence, children with desmoids should be treated synthetically with much caution, while surgery, chemotherapy or radiation is necessary.

This review also has some limitations. To begin with, crucial indices such as local recurrence rates cannot be compared directly among different treatment modalities, due to unignorable heterogeneity. For example, prognostic factor criteria are judged by various means, from imaging to symptoms. In addition, heterogeneity in population characteristics such as sex or age can significantly impact prognosis. The present review proposes that multicenter cooperation should constitute a unified research strategy to eliminate heterogeneity in order to yield convincing evidence, which would decide the best modality to treat desmoids. Secondly, data from different reports with varying levels of evidence inevitably caused some biases. With more evidence emerging, it would make systematic research possible to sift out high-quality data while simultaneously not leaving out too much information.

\section{Acknowledgements}

Not applicable.

\section{Funding}

No funding was received.

\section{Availability of data and materials}

Not applicable.

\section{Authors' contributions}

$\mathrm{ZZ}$ initially started this review, organized the literature and drafted the article. JS made critical revisions and contributed to drafting parts of the manuscript. TY retrieved literatures, collected and sorted crucial information. KZ and TL provided instructions on writing, as well as retrieving literatures, and made insightful revisions. All authors read and approved the final manuscript.

\section{Ethics approval and consent to participate}

Not applicable.

\section{Patient consent for publication}

Not applicable.

\section{Competing interests}

The authors declare that they have no competing interests.

\section{References}

1. Kofoed H, Kamby C and Anagnostaki L: Aggressive fibromatosis. Surg Gynecol Obstet 160: 124-127, 1985.

2. Rock MG, Pritchard DJ, Reiman HM, Soule EH and Brewster RC: Extra-abdominal desmoid tumors. J Bone Joint Surg Am Vol 66: 1369-1374, 1984. 
3. Michael J, Kaplan and, Britt-Marie and Ljung: Enzinger FM and Weiss SW (eds). Soft Tissue Tumors (1983) C.V. Mosby Co.,St Louis. American Journal of Otolaryngology, 1985.

4. Mackenzie HD: The fibromatoses: A clinicopathological concept. Br Med J 4: 277-281, 1972.

5. Musgrove JE and Mcdonald JR: Extra-abdominal desmoid tumors; their differential diagnosis and treatment. Arch Pathol (Chic) 45: 513-540, 1948.

6. Li Destri G, Ferraro MJ, Calabrini M, Pennisi M and Magro G: Desmoid-type fibromatosis of the mesentery: Report of a sporadic case with emphasis on differential diagnostic problems. Case Rep Med 2014, 850180, 2014.

7. Martínez Trufero J, Pajares Bernad I, Torres Ramón I, Hernando Cubero J and Pazo Cid R: Desmoid-type fibromatosis: Who, when, and how to treat. Curr Treat Options Oncol 18: 29, 2017.

8. Escobar C, Munker R, Thomas JO, Li BD and Burton GV: Update on desmoid tumors. Ann Oncol 23: 562-569, 2012

9. Nieuwenhuis MH, Lefevre JH, Bülow S, Järvinen H, Bertario L, Kernéis S, Parc Y and Vasen HF: Family history, surgery, and APC mutation are risk factors for desmoid tumors in familial adenomatous polyposis: An international cohort study. Dis Colon Rectum 54: 1229-1234, 2011.

10. Amary MF, Pauwels P, Meulemans E, Roemen GM, Islam L, Idowu B, Bousdras K, Diss TC, O'Donnell P and Flanagan AM Detection of beta-catenin mutations in paraffin-embedded sporadic desmoid-type fibromatosis by mutation-specific restriction enzyme digestion (MSRED): An ancillary diagnostic tool. Am J Surg Pathol 31: 1299-1309, 2007.

11. Rhim JH, Kim JH, Moon KC, Park SW, Sohn CH, Choi SH, Yun TJ and Chang KH: Desmoid-type fibromatosis in the head and neck: CT and MR imaging characteristics. Neuroradiology 55: 351-359, 2013.

12. Murphey MD, Ruble CM, Tyszko SM, Zbojniewicz AM, Potter BK and Miettinen M: From the archives of the AFIP: Musculoskeletal fibromatoses: Radiologic-pathologic correlation. Radiographics 29: 2143-2173, 2009.

13. Sinha A, Hansmann A, Bhandari S, Gupta A, Burling D, Rana S, Phillips RK, Clark SK and Goh V: Imaging assessment of desmoid tumours in familial adenomatous polyposis: Is state-of-the-art 1.5 T MRI better than 64-MDCT? Br J Radiol 85: e254-e261, 2012.

14. Dinauer PA, Brixey CJ, Moncur JT, Fanburg-Smith JC and Murphey MD: Pathologic and MR imaging features of benign fibrous soft-tissue tumors in adults. Radiographics 27: 173-187, 2007.

15. Robbin MR, Murphey MD, Temple HT, Kransdorf MJ and Choi JJ: Imaging of musculoskeletal fibromatosis Radiographics 21: 585-600, 2001

16. Salas S, Dufresne A, Bui B, Blay JY, Terrier P, Ranchere-Vince D, Bonvalot S, Stoeckle E, Guillou L, Le Cesne A, et al: Prognostic factors influencing Progression-free survival determined from a series of sporadic desmoid tumors: A Wait-and-See policy according to tumor presentation. J Clin Oncol 29: 3553-3558, 2011

17. Gari MK, Guraya SY, Hussein AM and Hego MM: Giant mesenteric fibromatosis: Report of a case and review of the literature. World J Gastrointest Surg 4: 79-82, 2012.

18. Ogawa T: Complete resection of a rectus abdominis muscle invaded by desmoid tumors and subsequent management with an abdominal binder: A case report. J Med Case Reps 12: 29, 2018.

19. Okamura S, Kitahara T, Tamai K, Minoji T, Takabatake H, Watanabe N, Yamamura N, Fukuchi N,Ebisui C, Yokouchi H, et al: Resection of a desmoid tumor originating from the greater omentum after surgery for colon cancer and liver metastasis-a case report. Gan To Kagaku Ryoho 45: 2444-2446, 2018 (In Japanese).

20. Howard JH and Pollock RE: Intra-abdominal and abdominal wall desmoid fibromatosis. Oncol Ther 4: 57-72, 2016.

21. Peng PD, Hyder O, Mavros MN, Turley R, Groeschl R, Firoozmand A, Lidsky M, Herman JM, Choti M, Ahuja N, et al: Management and recurrence patterns of desmoids tumors: A Multi-institutional analysis of 211 patients. Ann Surg Oncol 19: 4036-4042, 2012.

22. Tsagozis P, Stevenson JD, Grimer R and Carter S: Outcome of surgery for primary and recurrent desmoid-type fibromatosis. A retrospective case series of 174 patients. Ann Med Surg (Lond) 7: 14-19, 2017.

23. Janssen ML, Van Broekhoven DL, Cates JM, Bramer WM, Nuyttens JJ, Gronchi A, Salas S, Bonvalot S, Grünhagen DJ and Verhoef C: Meta-analysis of the influence of surgical margin and adjuvant radiotherapy on local recurrence after resection of sporadic desmoid-type fibromatosis. Br J Surg 104: 347-357, 2017.
24. Kujak JL, Liu PT, Johnson GB and Callstrom MR: Early experience with percutaneous cryoablation of extra-abdominal desmoid tumors. Skeletal Radiol 39: 175-182, 2010.

25. Leithner A, Gapp M, Leithner K, Radl R, Krippl P, Beham A and Windhager R: Margins in extra-abdominal desmoid tumors: A comparative analysis. J Surg Oncol 86: 152-156, 2004.

26. Smith K, Desai J, Lazarakis S and Gyorki D: Systematic review of clinical outcomes following various treatment options for patients with extraabdominal desmoid tumors. Ann Surg Oncol 25: 1544-1554, 2018.

27. Lev D, Kotilingam D, Wei C, Ballo MT, Zagars GK, Pisters PW, Lazar AA, Patel SR, Benjamin RS and Pollock RE: Optimizing treatment of desmoid tumors. J Clin Oncol 25: 1785-1791, 2007.

28. Gronchi A, Casali PG, Mariani L, Lo Vullo S, Colecchia M, Lozza L, Bertulli R, Fiore M, Olmi P, Santinami M and Rosai J: Quality of surgery and outcome in extra-abdominal aggressive fibromatosis: A series of patients surgically treated at a single institution. J Clin Oncol 21: 1390-1397, 2003.

29. Merchant NB, Lewis JJ, Woodruff JM, Leung DHY and Brennan MF: Extremity and trunk desmoid tumors: A multifactorial analysis of outcome. Cancer 86: 2045-2052, 1999.

30. Ballo MT, Zagars GK, Pollack A, Pisters PWT and Pollock RA: Desmoid tumor: Prognostic factors and outcome after surgery, radiation therapy, or combined surgery and radiation therapy. J Clin Oncol 17: 158-167, 1999.

31. Gronchi A, Le Péchoux C, Dei Tos AP, Le Cesne A, Marrari A, Penel N, Grignani G, Blay JY, Casali PG, Stoeckle E, et al: Sporadic desmoid-type fibromatosis: A stepwise approach to a non-metastasising neoplasm-A position paper from the Italian and the French Sarcoma Group. Ann Oncol 25: 578-583, 2014.

32. Cobianchi L, Ravetta V, Viera FT, Filisetti C, Siri B, Segalini E, Maestri M, Dominioni T, Alessiani M, Rossi S and Dionigi P: The challenge of extraabdominal desmoid tumour management in patients with Gardner's syndrome: Radiof requency ablation, a promising option. World J Surg Oncol 12: 361, 2014.

33. Tremblay KR, Lea WB, Neilson JC, King DM and Tutton SM: Percutaneous cryoablation for the treatment of extra-abdominal desmoid tumors. J Surg Oncol 120: 366-375, 2019.

34. Knudsen AL and Bülow S: Desmoid tumour in familial adenomatous polyposis. A review of literature. Fam Cancer 1: 111-119, 2001.

35. Eastley N, McCulloch T, Esler C, Hennig I, Fairbairn J, Gronchi A and Ashford R: Extra-abdominal desmoid fibromatosis: A review of management, current guidance and unanswered questions. Eur J Surg Oncol 42: 1071-1083, 2016.

36. Colombo C, Miceli R, Le Péchoux C, Palassini E, Honoré C, Stacchiotti S, Mir O, Casali PG, Dômont J, Fiore M, et al: Sporadic extra abdominal wall desmoid-type fibromatosis: Surgical resection can be safely limited to a minority of patients. Eur J Cancer 51: 186-192, 2015.

37. Bonvalot $\mathrm{S}$, Ternès $\mathrm{N}$, Fiore $\mathrm{M}$, Bitsakou $\mathrm{G}$, Colombo $\mathrm{C}$, Honoré C, Marrari A, Le Cesne A, Perrone F, Dunant A and Gronchi A: Spontaneous regression of primary abdominal wall desmoid tumors: More common than previously thought. Ann Surg Oncol 20: 4096-4102, 2013.

38. Bonvalot S, Eldweny H, Haddad V, Rimareix F, Missenard G, Oberlin O, Vanel D, Terrier P, Blay JY, Le Cesne A and Le Péchoux C: Extra-abdominal primary fibromatosis: Aggressive management could be avoided in a subgroup of patients. Eur J Surg Oncol 34: 462-468, 2008.

39. Cho JY, Gupta S, Cho HS, Park MS, Mok SJ, Han I and Kim HS: Role of nonsteroidal anti-inflammatory drug in treatment of extra-abdominal desmoid tumors. Clin Orthop Surg 10: 225-233, 2018

40. Zhao J, Wang Q, Li X, Hu X and Shen H: Effective high intensity focused ultrasound treatment in recurrent aggressive breast fibromatosis: A case report. Onco Targets Ther 12: 5251-5256, 2019.

41. De Bree E, Zoras O, Hunt JL, Takes RP, Suárez C, Mendenhall WM, Hinni ML, Rodrigo JP, Shaha AR, Rinaldo A, et al: Desmoid tumors of the head and neck: A therapeutic challenge. Head Neck 36: 1517-1526, 2014.

42. Briand S, Barbier O, Biau D, Bertrand-Vasseur A and Gouin F: Wait-and-See policy as a First-line management for extra-abdominal desmoid tumors. J Bone Joint Surg Am 96: 631-638, 2014

43. Kamath SS, Parsons JT, Marcus RB, Zlotecki RA and Scarborough MT: Radiotherapy for local control of aggressive fibromatosis. Int J Radiat Oncol Biol Phys 36: 325-328, 1996. 
44. Goy BW, Lee SP, Eilber F, Dorey F, Eckardt J, Fu YS, Juillard GJ and Selch MT: The role of adjuvant radiotherapy in the treatment of resectable desmoid tumors. Int J Radiat Oncol Biol Phys 39: 659-665, 1997.

45. Boland PJ, Leung DH, Woodruff JM and Brennan MF: The enigma of desmoid tumors. Ann Surg 229: 866-873, 1999.

46. Guadagnolo BA, Zagars GK and Ballo MT: Long-term outcomes for desmoid tumors treated with radiation therapy. Int J Radiat Oncol Biol Phys 71: 441-447, 2008.

47. Bishop AJ, Zarzour MA, Ratan R, Torres KE, Feig BW, Wang WL, Lazar AJ, Moon BS, Roland CL and Guadagnolo BA: Long-Term outcomes for patients with desmoid fibromatosis treated with radiation therapy: A 10-Year Update and Re-evaluation of the role of radiation therapy for younger patients. Int J Radiat Oncol Biol Phys 103: 1167-1174, 2019.

48. Chen Y, Chen Y and Liu Y: Abnormal presentation of aggressive fibromatosis after radiotherapy for keloids case report and brief literature review. Ann Plast Surg 83: 104-107, 2019.

49. Nuyttens JJ, Rust PF, Thomas CR Jr and Turrisi AT III: Surgery versus radiation therapy for patients with aggressive fibromatosis or desmoid tumors: A comparative review of 22 articles. Cancer 88: 1517-1523, 2000.

50. Pritchard DJ, Nascimento AG and Petersen IA: Local control of extra-abdominal desmoid tumors. J Bone Joint Surg Am 78: 848-854, 1996.

51. Constantinidou A, Jones RL, Scurr M, Al-Muderis O and Judson I: Advanced aggressive fibromatosis: Effective palliation with chemotherapy. Acta Oncologica 50: 455-461, 2011.

52. Sze H and Yeung MW: Fibromatosis of the neck causing airway obstruction managed effectively with weekly low-dose methotrexate and vinblastine. Hong Kong Med J 15: 221-223, 2009.

53. Chaudhary P: Mesenteric fibromatosis. Int J Colorectal Dis 29: 1445-1451, 2014.

54. Skapek SX, Hawk BJ, Hoffer FA, Dahl GV, Granowetter L, Gebhardt MC, Ferguson WS and Grier HE: Combination chemotherapy using vinblastine and methotrexate for the treatment of progressive desmoid tumor in children. J Clin Oncol 16: 3021-3027, 1998.

55. Janinis J, Patriki M, Vini L, Aravantinos G and Whelan JS: The pharmacological treatment of aggressive fibromatosis: A systematic review. Ann Oncol 14: 181-190, 2003.

56. Kasper B: Systemic treatment approaches for sporadic desmoid-type fibromatosis: Scarce evidence and recommendations. Oncol Res Treat 38: 244-248, 2015.

57. Penel N, Le Cesne AL, Bonvalot S, Giraud A, Bompas E, Rios M, Salas S, Isambert N, Boudou-Rouquette P, Honore C, et al: Surgical versus non-surgical approach in primary desmoid-type fibromatosis patients: A nationwide prospective cohort from the French Sarcoma Group. Eur J Cancer 83: 125-131, 2017.

58. Kasper B, Gruenwald V, Reichardt P, Bauer S, Rauch G, Limprecht R, Sommer M, Dimitrakopoulou-Strauss A, Pilz L, Haller F and Hohenberger P: Imatinib induces sustained progression arrest in RECIST progressive desmoid tumours: Final results of a phase II study of the German Interdisciplinary Sarcoma Group (GISG). Eur J Cancer 76 60-67, 2017.

59. Penel N, Le Cesne AL, Bui BN, Perol D, Brain EG, Ray-Coquard I, Guillemet C, Chevreau C, Cupissol D, Chabaud S, et al: Imatinib for progressive and recurrent aggressive fibromatosis (desmoid tumors): An FNCLCC/French Sarcoma Group phase II trial with a long-term follow-up. Ann Oncol 22: 452-457, 2011.

60. Chugh R, Wathen JK, Patel SR, Maki RG, Meyers PA, Schuetze SM, Priebat DA, Thomas DG, Jacobson JA, Samuels BL, et al: Efficacy of imatinib in aggressive fibromatosis: Results of a phase II multicenter sarcoma alliance for research through collaboration (SARC) trial. Clin Cancer Res 16: 4884-4891, 2010.

61. Liu LP, Ho RL, Chen GG and Lai PB: Sorafenib inhibits hypoxia-inducible factor- $1 \alpha$ synthesis: Implications for antiangiogenic activity in hepatocellular carcinoma. Clin Cancer Res 18: 5662-5671,2012.

62. Gonçalves A, Monges G, Yang Y, Palmerini F, Dubreuil P, Noguchi T, Jacquemier J, Di Stefano D, Delpero JR, Sobol H and Bertucci F: Response of a KIT-positive Extra-abdominal fibromatosis to imatinib mesylate and KIT genetic analysis. J Natl Cancer Inst 98: 562-563, 2006.
63. Kim S, Yazici YD, Calzada G, Wang ZY, Younes MN, Jasser SA, El-Naggar AK and Myers JN: Sorafenib inhibits the angiogenesis and growth of orthotopic anaplastic thyroid carcinoma xenografts in nude mice. Mol Cancer Ther 6: 1785-1792, 2007.

64. Liu L, Cao Y, Chen C, Zhang X, McNabola A, Wilkie D, Wilhelm S, Lynch $M$ and Carter C: Sorafenib blocks the $\mathrm{RAF} / \mathrm{MEK} / \mathrm{ERK}$ pathway, inhibits tumor angiogenesis, and induces tumor cell apoptosis in hepatocellular carcinoma model PLC/PRF/5. Cancer Res 66: 11851-11858, 2006

65. Mace J, Biermann JS, Sondak V, McGinn C, Hayes C, Thomas D and Baker L: Response of extraabdominal desmoid tumors to therapy with imatinib mesylate. Cancer 95: 2373-2379, 2002.

66. Cho NL, Carothers AM, Rizvi H, Hasson RM, Redston M and Bertagnolli MM: Immunohistochemical and molecular analysis of tyrosine kinase activity in? desmoid tumors. J Surg Res 173: $0-326,2012$

67. Skubitz KM, Manivel JC, Clohisy DR and Frolich JW: Response of imatinib-resistant extra-abdominal aggressive fibromatosis to sunitinib: Case report and review of the literature on response to tyrosine kinase inhibitors. Cancer Chemother Pharmacol 64: 635-640, 2009.

68. Jo JC, Hong YS, Kim KP, Lee JL, Lee J, Park YS, Kim SY, Ryu JS, Lee JS and Kim TW: A prospective multicenter phase II study of sunitinib in patients with advanced aggressive fibromatosis. Invest New Drugs 32: 369-376, 2014.

69. Gounder MM, Lefkowitz RA, Keohan ML, D'Adamo DR, Hameed M, Antonescu CR, Singer S, Stout K, Ahn L and Maki RG: Activity of sorafenib against desmoid Tumor/Deep fibromatosis. Clin Cancer Res 17: 4082-4090, 2011.

70. Braggio D, Koller D, Jin F, Siva N, Zewdu A, Lopez G, Batte K, Casadei L, Welliver M, Strohecker AM, et al: Autophagy inhibition overcomes sorafenib resistance in S45F-mutated desmoid tumors. Cancer 125: 2693-2703, 2019.

71. Shimizu K, Hamada S, Sakai T, Koike H, Yoshida M and Nishida Y: Efficacy of low-dose chemotherapy with methotrexate and vinblastine for patients with extra-abdominal desmoid-type fibromatosis: A systematic review. Jpn J Clin Oncol 50: 419-424, 2020

72. Skapek SX, Ferguson WS, Granowetter L, Devidas M, Perez-Atayde AR, Dehner LP, Hoffer FA, Speights R, Gebhardt MC, Dahl GV, et al: Vinblastine and methotrexate for desmoid fibromatosis in children: Results of a pediatric oncology group phase II trial. J Clin Oncol 25: 501-506, 2007.

73. Azzarelli A, Gronchi A, Bertulli R, Tesoro JD, Baratti D, Pennacchioli E, Dileo P, Rasponi A, Ferrari A, Pilotti S and Casali PG: Low-dose chemotherapy with methotrexate and vinblastine for patients with advanced aggressive fibromatosis. Cancer 92: 1259-1264, 2001.

74. Reich S, Overberg-Schmidt US, Bührer C and Henze G: Low-dose chemotherapy with vinblastine and methotrexate in childhood desmoid tumors. J Clin Oncol 17: 1086, 1999.

75. Meazza C, Bisogno G, Gronchi A, Fiore M, Cecchetto G, Alaggio R, Milano GM, Casanova M, Carli M and Ferrari A: Aggressive fibromatosis in children and adolescents: The Italian experience. Cancer 116: 233-240, 2010.

76. Ananth P, Werger A, Voss S, Rodriguez-Galindo C and Janeway KA: Liposomal doxorubicin: Effective treatment for pediatric desmoid fibromatosis. Pediatr Blood Cancer: Dec 1, 2017 (Epub ahead of print). doi: 10.1002/pbc.26375.

77. Weiss AJ, Horowitz S, Lackman RD and Lackmen RD: Therapy of desmoid tumors and fibromatosis using vinorelbine. Am J Clin Oncol 22: 193-195, 1999.

78. Gronchi A, Colombo C, Le Péchoux C, Dei Tos AP, Le Cesne A, Marrari A, Penel N, Grignani G, Blay JY, Casali PG, et al: Sporadic desmoid-type fibromatosis: A stepwise approach to a non-metastasising neoplasm-a position paper from the Italian and the French Sarcoma Group. Ann Oncol 25: 578-583, 2014.

79. van Dalen EC, Michiels EM, Caron HN and Kremer LC: Different anthracycline derivates for reducing cardiotoxicity in cancer patients. Cochrane Database Syst Rev 4: CD005006, 2006.

80. Wehl G, Rossler J, Otten JE, Boehm N, Uhl M, Kontny U and Niemeyer C: Response of progressive fibromatosis to therapy with liposomal doxorubicin. Onkologie 27: 552-556, 2004.

81. Constantinidou A, Jones RL, Scurr M, Al-Muderis O and Judson I: Pegylated liposomal doxorubicin, an effective, well-tolerated treatment for refractory aggressive fibromatosis. Eur J Cancer 45: 2930-2934, 2009. 
82. Shkalim Zemer V, Toledano H, Kornreich L, Freud E, Atar E, Avigad S, Feinberg-Gorenshtein G, Fichman S, Issakov J, Dujovny $\mathrm{T}$, et al: Sporadic desmoid tumors in the pediatric population: A single center experience and review of the literature. J Pediatr Surg 52: 1637-1641, 2017.

83. Ayala AG, Ro JY, Goepfert H, Cangir A, Khorsand J and Flake G: Desmoid fibromatosis: A clinicopathologic study of 25 children. Semin Diagn Pathol 3: 138-150, 1986.

84. Bonvalot S, Rimareix F, Causeret S, Le Péchoux C, Boulet B Terrier P, Le Cesne A and Muret J: Hyperthermic isolated limb perfusion in locally advanced soft tissue sarcoma and progressive desmoid-type fibromatosis with TNF $1 \mathrm{mg}$ and melphalan (T1-M HILP) is safe and efficient. Ann Surg Oncol 16: 3350-3357, 2009

85. van Broekhoven DL, Deroose JP, Bonvalot S, Gronchi A, Grünhagen DJ, Eggermont AM and Verhoef C: Isolated limb perfusion using tumour necrosis factor $\alpha$ and melphalan in patients with advanced aggressive fibromatosis. Br J Surg 101: 1674-1680, 2014.

86. Raney B, Evans A, Granowetter L, Schnaufer L and Littman P: Nonsurgical management of children with recurrent OT unresectable fibromatosis. Pediatrics 79: 394-398, 1987.

87. Weiss AJ and Lackman RD: Low-dose chemotherapy of desmoid tumors. Cancer 64: 1192-1194, 1989.

88. Cole NM: Extra-abdominal desmoid tumors. J Bone Joint Surg Br 53: 373-377, 1979 .

89. Raney RB J: Chemotherapy for children with aggressive fibromatosis and Langerhans' cell histiocytosis. Clin Orthop Relat Res: 58-63, 1991

90. Kummar S, O'Sullivan Coyne G, Do KT, Turkbey B, Meltzer PS, Polley E, Choyke PL, Meehan R, Vilimas R, Horneffer Y, et al: Clinical Activity of the $\gamma$-Secretase inhibitor PF-03084014 in adults with desmoid tumors (Aggressive Fibromatosis). J Clin Oncol 35: 1561-1569, 2017.

91. Agresta L, Kim H, Turpin BK, Nagarajan R, Plemmons A, Szabo S, Dasgupta R, Sorger JI and Pressey JG: Pazopanib therapy for desmoid tumors in adolescent and young adult patients. Pediatr Blood Cancer 65: e26968, 2018.

92. Rombouts SJE, Vogel JA, Van Santvoort HC, van Lienden KP, van Hillegersberg R, Busch OR, Besselink MG and Molenaar IQ Systematic review of innovative ablative therapies for the treatment of locally advanced pancreatic cancer. Br J Surg 102: 182-193, 2015.

93. Zhou Y: High-Intensity focused ultrasound treatment for advanced pancreatic Cancer. Gastroenterol Res Pract 2014 205325,2014

94. Grimaldi MC, Trentin C, Gullo RL and Cassano E: Fibromatosis of the breast mimicking cancer: A case report. Radiol Case Rep 13: 1-5, 2017.

95. Haar GT and Coussios C: High intensity focused ultrasound Past, present and future. Int J Hyperthermia 23: 85-87, 2007.

96. Ghanouni P, Dobrotwir A, Bazzocchi A, Bucknor M, Bitton R, Rosenberg J, Telischak K, Busacca M, Ferrari S, Albisinni U, et al: Magnetic resonance-guided focused ultrasound treatment of extra-abdominal desmoid tumors: A retrospective multicenter study. Eur Radiol 27: 732-740, 2017.

97. Shi Y,Huang Y,Zhou M, Ying X and Hu X: High-intensity focused ultrasound treatment for intra-abdominal desmoid tumors: A report of four cases. J Med Ultrasonics 43: 279-284, 2016.

98. Wang Y, Wang W and Tang J: Ultrasound-guided high intensity focused ultrasound treatment for extra-abdominal desmoid tumours: Preliminary results. Int J Hyperthermia 27: 648-653, 2011.

99. Zhao WP, Han ZY, Zhang J, Yu XL, Cheng ZG, Zhou X and Liang P: Early experience: High-intensity focused ultrasound treatment for intra-abdominal aggressive fibromatosis of failure in surgery. Br J Radiol 89: 20151026, 2016.

100. Kurup AN and Callstrom MR: Image-guided percutaneous ablation of bone and soft tissue tumors. Semin Intervent Radiol 27: 276-284, 2010.

101. Kurup AN and Callstrom MR: Expanding role of percutaneous ablative and consolidative treatments for musculoskeletal tumours. Clin Radiol 72: 645-656, 2017.

102. Schmitz JJ, Schmit GD, Atwell TD, Callstrom MR, Kurup AN Weisbrod AJ and Morris JM: Percutaneous cryoablation of extraabdominal desmoid tumors: A 10-year experience. Am J Roentgenol 207: 190-195, 2016.

103. Havez M, Lippa N, Al-Ammari S, Kind M and Cornelis F: Percutaneous image-guided cryoablation in inoperable extra-abdominal desmoid tumors: A study of tolerability and efficacy. Cardiovasc Intervent Radiol 37: 1500-1506, 2014.
104. Baek JH, Lee JH, Jin YS, Bae JI and Na DG: Complications encountered in the treatment of benign thyroid nodules with US-guided radiofrequency ablation: A multicenter study. Radiology 262: 335-342, 2012.

105. Kim AH, Ko HK, Won JY and Lee DY: Percutaneous radiofrequency ablation: A novel treatment of facial venous malformation. J Vasc Surg 50: 424-427, 2009.

106. Barrow E, Newton K, Rajashanker B, Lee S, Evans DG and Hill J: Successful radiofrequency ablation of an anterior abdominal wall desmoid in familial adenomatous polyposis. Colorectal Dis 15: e160-e163, 2013.

107. Ilaslan H, Schils J, Joyce M, Marks K and Sundaram M: Radiofrequency ablation: Another treatment option for local control of desmoid tumors. Skeletal Radiol 39: 169-173, 2010.

108. Tsz-Kan T, Man-Kwong C, Shang-Jen JS, Ying-Lee L, Wai Man-Wah A and Hon-Shing F: Radiofrequency ablation of recurrent fibromatosis. J Vasc Int Radiol 18: 147-150, 2007.

109. Ko HK and Kang HG: Radiofrequency ablation for the treatment of recurring desmoid tumors after repeated surgical resection: Usefulness of the moving-tip technique. Curr Orthop Pract 24: 547-551, 2013

110. Eastley NC, Hennig IM, Esler CP and Ashford RU: Nationwide trends in the current management of desmoid (Aggressive) fibromatosis. Clin Oncol 27: 362-368, 2015.

111. de Camargo VP, Keohan ML, D'Adamo DR, Antonescu CR, Brennan MF, Singer S, Ahn LS and Maki RG: Clinical outcomes of systemic therapy for patients with deep fibromatosis (desmoid tumor). Cancer 116: 2258-2265, 2010

112. Tanaka K, Yoshikawa R, Yanagi H, Gega M, Fujiwara Y, Hashimoto-Tamaoki T, Hirota S, Tsujimura T and Tomita $\mathrm{N}$ : Regression of sporadic intra-abdominal desmoid tumour following administration of non-steroidal anti-inflammatory drug. World J Surg Oncol 6: 17, 2008

113. Sturt NJH, Phillips RK and Clark SK: High-dose tamoxifen and sulindac as first-line treatment for desmoid tumors. Cancer 101: $652,2004$.

114. Lackner H, Urban C, Kerbl R, Schwinger W and Beham A Noncytotoxic drug therapy in children with unresectable desmoid tumors. Cancer 80: 334-340, 1997.

115. Bocale D, Rotelli MT, Cavallini A and Altomare DF: Anti-oestrogen therapy in the treatment of desmoid tumours: A systematic review. Colorectal Dis 13: e388-e395, 2011.

116. Okuno S: The enigma of desmoid tumors. Curr Treat Options Oncol 7: 438-443, 2006.

117. Yaffe K, Krueger K, Sarkar S, Grady D, Barrett-Connor E, Cox DA and Nickelsen T; Multiple Outcomes of Raloxifene Evaluation Investigators: Cognitive function in postmenopausal women treated with raloxifene. N Engl J Med 344: 1207-1213, 2001.

118. Ettinger B, Black DM, Mitlak BH, Knickerbocker RK, Nickelsen T, Genant HK, Christiansen C, Delmas PD, Zanchetta JR, Stakkestad J, et al: Reduction of vertebral fracture risk in postmenopausal women with osteoporosis treated with raloxifene: Results from a 3-year randomized clinical trial. Multiple Outcomes of Raloxifene Evaluation (MORE) Investigators. JAMA 282: 637-645, 1999.

119. Cummings SR, Eckert S, Krueger KA, Grady D, Powles TJ, Cauley JA, Norton L, Nickelsen T, Bjarnason NH, Morrow M, et al: The effect of raloxifene on risk of breast cancer in postmenopausal Women: Results From the MORE randomized trial. Multiple Outcomes of Raloxifene Evaluation. JAMA 281: 2189-2197, 1999.

120. Delmas PD, Bjarnason NH, Mitlak BH, Ravoux AC, Shah AS, Huster WJ, Draper M and Christiansen C: Effects of raloxifene on bone mineral density, serum cholesterol concentrations, and uterine endometrium in postmenopausal women. N Engl J Med 337: 1641-1647, 1997.

121. Desurmont T, Lefèvre JH, Shields C, Colas C, Tiret E and Parc Y: Desmoid tumour in familial adenomatous polyposis patients: Responses to treatments. Fam Cancer 14: 31-39, 2015.

122. Quast DR, Schneider R, Burdzik E, Hoppe S and Möeslein G: Long-term outcome of sporadic and FAP-associated desmoid tumors treated with high-dose selective estrogen receptor modulators and sulindac: A single-center long-term observational study in 134 patients. Fam Cancer 15: 31-40, 2016.

123. Bauernhofer T, Stöger H, Schmid M, Smola M, Gürtl-Lackner B, Höfler G, Ranner G, Reisinger E and Samonigg H: Sequential treatment of recurrent mesenteric desmoid tumor. Cancer 77: 1061-1065, 1996. 
124. Skapek SX, Anderson JR, Hill DA, Henry D, Spunt SL, Meyer W, Kao S, Hoffer FA, Grier HE, Hawkins DS and Raney RB: Safety and efficacy of high-dose tamoxifen and sulindac for desmoid tumor in children: Results of a Children's Oncology Group (COG) phase II study. Pediatr Blood Cancer 60: 1108-1112, 2013

125. Wang Z, Wu J, Tian X and Hao C: Targeted therapy of desmoid-type fibromatosis: Mechanism, current situation, and future prospects. Front Med 13: 427-437, 2019.

126. Tsukada K, Church JM, Jagelman DG, Fazio VW, McGannon E, George CR, Schroeder T, Lavery I and Oakley J: Noncytotoxic drug therapy for intra-abdominal desmoid tumor in patients with familial adenomatous polyposis. Dis Colon Rectum 35: 29-33, 1992.

127. Huang PW and Tzen CY: Prognostic factors in desmoid-type fibromatosis. Pathology 42: 147-150, 2010.

128. Nishida Y, Tsukushi S, Shido Y, Urakawa H, Arai E and Ishiguro N: Transition of treatment for patients with extra-abdominal desmoid tumors: Nagoya University modality. Cancers 4: 88-99, 2012.

129. Yang S, Wang X, Jiang H, Wang Y, Li Z and Lu H: Effective treatment of aggressive fibromatosis with celecoxib guided by genetic testing. Cancer Biol Ther 18: 757-760, 2017.

130. Wang YC and Wong JU: Complete remission of pancreatic head desmoid tumor treated by COX-2 inhibitor-a case report. World J Surg Oncol 14: 190, 2016.

131. Waddell W: Indomethacin and ascorbate inhibit desmoid tumors. J Surg Oncol 15: 85-90, 2010.

132. Yildiz F, Kars A, Cengiz M, Yildiz O, Akyürek S, Selek U, Ozyigit G and Atahan IL: 1,25-Dihydroxy vitamin D3: Can it be an effective therapeutic option for aggressive fibromatosis. Med Hypotheses 64: 333-336, 2005.
133. Ferah Y, Ayse K, Mustafa C, Ugur S, Murat G and Lale AI: Possible therapeutic role of vitamin D-3 in aggressive fibromatosis. Jpn J Clin Oncol 34: 472-475, 2004.

134. Leithner A, Schnack B, Katterschafka T, Wiltschke C, Amann G, Windhager R, Kotz R and Zielinski CC: Treatment of extra-abdominal desmoid tumors with interferon-alpha with or without tretinoin. J Surg Oncol 73: 21-25, 2000.

135. Goto T, Nemoto T, Ogura K, Hozumi T and Funata N: Successful treatment of desmoid tumor of the chest wall with tranilast: A case report. J Med Case Rep 4: 384, 2010.

136. Nakada I, Ubukata H, Goto Y, Watanabe Y, Sato S, Tabuchi T and Soma T: Prednisolone therapy for intra-abdominal desmoid tumors in a patient with familial adenomatous polyposis. J Gastroenterol 32: 255-259, 1997.

137. Umemoto S, Makuuchi H, Amemiya T, Yamaguchi H, Oka S, Owada $\mathrm{T}$ and Koizumi K: Intra-abdominal desmoid tumors in familial polyposis coli: A case report of tumor regression by prednisolone therapy. Dis Colon Rectum 34: 89-93, 1991.

138. Waddell WR, Cerner RE and Reich MP: Nonsteroid antiinflammatory drugs and tamoxifen for desmoid tumors and carcinoma of the stomach. J Surg Oncol 22: 197-211, 1983.

139. Waddell DWR and Gerner RE: Indomethacin and ascorbate inhibit desmoid tumors. J Surg Oncol 15: 85-90, 1980.

140. Crago AM, Denton B, Salas S, Dufresne A, Mezhir JJ, Hameed M, Gonen M, Singer S and Brennan MF: A prognostic nomogram for prediction of recurrence in desmoid fibromatosis. Ann Surg 258: 347-353, 2013.

141. Faulkner L: Pediatric desmoid tumor: Retrospective analysis of 63 cases. J Clin Oncol 13: 2813-2818, 1995. International (CC BY-NC-ND 4.0) License. 